\title{
Short-term Effects of a Systematized Bladder Training Program for Idiopathic Overactive Bladder: A Prospective Study
}

\author{
Hahn-Ey Lee, Sung Yong Cho ${ }^{1}$, Sangim Lee, Myong Kim, Seung-June Oh \\ Department of Urology, Seoul National University Hospital, Seoul; \\ ${ }^{1}$ Department of Urology, SMG-SNU Boramae Medical Center, Seoul, Korea
}

\begin{abstract}
Purpose: This study was to investigate whether a systematized bladder training (BT) program is effective for patients with idiopathic overactive bladder $(\mathrm{OAB})$.

Methods: A prospective study was conducted on 105 patients with OAB from March 2009 to November 2011. We developed a 30 minutes BT program, which consisted of first, refraining from going to the bathroom after feeling an urge to void, second, in order to stop thinking about voiding, ceasing action and thought temporarily, and third, performing pelvic floor exercises 5 to 6 times. Before and after BT, the patients filled out voiding diaries as well as the following questionnaires; International Consultation on Incontinence Questionnaire for overactive bladder (ICIQ-OAB), International Prostate Symptom Score (IPSS), overactive bladder questionnaire (OAB-q), the short form 36-item health survey (SF-36) questionnaire, the work productivity and activity impairment questionnaire, and a patients' perception of treatment benefit (PPTB).

Results: A final analysis was performed from on 85 patients ( 38 male, 47 female) with idiopathic OAB. After the first BT, the results of the ICIQ-OAB showed improvement in frequency, nocturia, and urgency $(\mathrm{P}<0.05)$, and all domains of IPSS questionnaires showed significant improvement $(\mathrm{P}<0.05)$. Among the $\mathrm{SF}-36$ domains, the role-physical domain showed significant improvement after the first $\mathrm{BT}$, and the general health domain showed significant improvement after the second. The voiding diaries showed statistically significant changes in maximal voided volume after the first $\mathrm{BT}$, and nocturia index and nocturnal polyuria index after the second BT. According to the PPTB questionnaire, the perceived usefulness of BT increased after each session, and almost all of the patients replied that BT improved their symptoms.

Conclusions: Our results demonstrated that BT was effective in improving many OAB related symptoms and quality of life in patients with idiopathic OAB. More clinical application of BT could be implemented in the future.
\end{abstract}

Keywords: Behavior modification; Overactive urinary bladder; Quality of life

\section{INTRODUCTION}

Overactive bladder $(\mathrm{OAB})$ is defined by the International Continence Society as symptoms of urgency, with or without urge incontinence, usually accompanied with frequency and nocturia [1]. Urgency is a sudden and compelling desire to pass urine that cannot easily be deferred, and is different from the normal strong desire to void in healthy persons. Idiopathic $\mathrm{OAB}(\mathrm{iOAB})$ is defined as $\mathrm{OAB}$ without underlying urological or neurologic diseases [2]. OAB has a major impact on depression, social isolation and a decline in general health $(\mathrm{GH})$ and quality of life.
The International Consultation on Incontinence (ICI) guidelines recommend pharmacotherapy and conservative treatment as a first-line therapy in OAB patients. Such conservative treatments include diet modification, pelvic floor muscle exercise, biofeedback, timed voiding and other bladder control programs that provide instructions to urgency or urge incontinence. Antimuscarinics can be added if these measures fail to control symptoms $[3,4]$.

Such behavioral intervention is suitable for primary care setting. Bladder training (BT) has been proven to improve urge urinary incontinence, and resolution rates have been reported
Corresponding author: Seung-June Oh

Department of Urology, Seoul National University Hospital,

Seoul National University College of Medicine, 101 Daehak-ro, Jongno-gu,

Seoul 110-744, Korea

Tel: +82-2-2072-2406 / Fax: +82-2-742-4665 / E-mail: sjo@snu.ac.kr

Submitted: March 12, 2013 / Accepted after revision: March 30, 2013
This is an Open Access article distributed under the terms of the Creative Commons Attribution Non-Commercial License (http://creativecommons.org/licenses/by-nc/3.0/) which permits unrestricted non-commercial use, distribution, and reproduction in any medium, provided the original work is properly cited. 
to range from $12 \%$ to $73 \%$, and improvement rates from $57 \%$ to $87 \%$ [5]. However, such protocols for BT vary from study to study [6]. Very few studies report on its efficacy, and there are even less prospective studies, Therefore, we aimed to investigate the efficacy of $\mathrm{BT}$ in patients with $\mathrm{iOAB}$, using a systematized protocol.

\section{MATERIALS AND METHODS}

We prospectively enrolled 105 patients who presented with $\mathrm{OAB}$ from March 2009 to November 2011 in a BT program at our institution. Inclusion criteria were male and female patients more than 20 years old with iOAB. Patients who already took stable medications for $\mathrm{OAB}$ were included in the study, if they meet the inclusion criteria. We did not change the prescribed drugs; instead we only administered BT. Patients who were literate, agreed to informed consent, and willingly participated were included in the study. We excluded patients with a previous history of genito-urinary surgery, radical pelvic surgery, neurologic conditions such as cerebrovascular accidents, Parkinson's disease, and spinal cord injuries. Medical history was taken, and clinical data was collected at the time of the first visit using a frequency-volume chart for 3 days, uroflowmetry with a measurement of postvoid residual urine volume, complete blood cell count test, test for electrolyte chemistry, urinalysis with microscopy, and urine culture to confirm underlying conditions.

We developed a 30 minutes education program, modified from our experience in a previous education program developed at our institution used to treat nocturia [7]. The BT program we developed consisted of (1) education of normal daytime voiding frequency and amount, (2) watching videos about normal physiology of storing and emptying function of urine, (3) education of holding urine until a certain goal, and then aiming to increase the amount by $50 \mathrm{~mL}$ within 2 weeks, (4) then BT by first, refraining from going to the bathroom after feeling an urge to void, second, temporary cessation of action and thought, in order to stop thinking about voiding, and third, performing pelvic floor exercises 5 to 6 times, and (5) feedback and problem shooting with a specialized nurse practitioner (sl). Patients received reinforcement BT of the same educational content 1 month after the first BT.

We obtained baseline questionnaires such as the International Prostate Symptom Score (IPSS), and International Consultation on Incontinence Questionnaire-Overactive bladder (ICIQ-
$\mathrm{OAB})$. The ICIQ questionnaires were previously linguistically validated by bilingual translators and approved for use by the International Consultation on Incontinence Modular Questionnaire Advisory Board (http://www.iciq.net/index.html). Patients completed overactive bladder questionnaires (OAB-q) which were also previously validated into Korean $[8,9]$, as well as the Korean version of the short form 36-item health survey (SF-36) [10]. The Korean version of the SF-36 has been validated in previous studies and our study uses it with authorization $[11,12]$. The SF-36 questionnaire consists of 8 domains and 36 questions that aim to evaluate both physical and mental healthrelated quality of life (HRQoL). It consists of eight domains which are physical functioning (PF, 10 items), GH (5 items), mental health (MH, 5 items), bodily pain (BP, 2 items), rolephysical (RP, 4 items), role-emotional (RE, 3 items), social functioning (SF, 2 items) and vitality (VT, 4 items). The higher the score sum, the higher the HRQoL [11]. A work productivity and activity impairment questionnaire (WPAI-GH) was also obtained before and after BT [13]. Patients' perception of treatment benefit (PPTB) was graded as no benefit, little benefit, or much benefit to measure the level of self-perceived improvement with BT [14]. Before BT, and after each session, patients were asked to complete the above-mentioned questionnaires. In addition, we developed a questionnaire which evaluated the perspective of BT and analyzed the responses we obtained after each BT session. They also filled out voiding diaries before and after each BT session.

Patients who did not return after each BT session were contacted by telephone of the nurse practitioner and asked questions to evaluate the self-perceived improvement rate of BT at the end of the study period. The primary outcome was urinary parameters measured by ICIQ-OAB, IPSS, OAB-q, and the secondary outcome was daytime and nocturnal number of voids.

A descriptive analysis was performed with the independent t-test method. A 2-sided chi-square test analysis was performed using the IBM SPSS ver. 18.0 (IBM Co., Armonk, NY, USA). A $\mathrm{P}$-value lower than 0.05 was considered to be statistically significant. This study was approved by the Institutional Review Board of Seoul National University Hospital (0812-010-264).

\section{RESULTS}

Eighty-five patients with $\mathrm{IOAB}$ were found to be eligible for analysis. The demographics of these patients were as following. The average age of the patients was $56.7 \pm 15.9$ years. Thirty-eight 
patients (44.7\%) were male, and 47 (55.3\%) were female. The average follow up period was $13.5 \pm 12.8$ weeks. Their socioeconomic status and voiding-related behavioral factors were also shown in Table 1.

The changes of questionnaires before and after each BT session were recorded and analyzed. After the first $\mathrm{BT}$ session the ICIQ-OAB showed improvement in frequency, nocturia, and urgency $(P<0.05)$, although incontinence did not show significant improvement. All domains of IPSS questionnaires also showed significant improvement $(\mathrm{P}<0.05)$. Among the SF-36 domains, the RP domain showed significant improvement after the first BT, and the GH domain showed significant improvement after the second BT (Table 2). After the second BT session, compared to the improvement after the first BT session, the improvement was not statistically significant, however, the improvement of the GH domain of the SF-36 questionnaire was significant. The results of the WPAI-GH obtained before and after BT are listed in Table 3. The patients reported that after BT, they missed less work hours, and worked more hours, although these changes were not statistically significant.

The results of the PPTB after BT were analyzed (Table 4). Sixty-three patients (91.3\%) replied that their symptoms improved after the first BT, and 37 patients (94.8\%) replied that the second session of BT improved their symptoms after completion of BT. According to a self-developed questionnaire evaluation the patient's perspective of BT, after each BT session, patients answered that strong contraction of pelvic muscles was most useful in holding urine, and that incontinence when holding urine was the most difficult factor during BT.

The voiding diaries showed statistically significant changes after the first BT in maximal voided volume, and after the second BT, nocturia index and nocturnal polyuria index showed significant improvement after the second BT session compared with the first BT (Table 5).

\section{DISCUSSION}

$\mathrm{OAB}$ is a common distressing condition and its prevalence increases with age [15]. Such a condition not only lowers the productivity and quality of life of the patients, but also increases socioeconomic costs, which is why it deserves attention [16].

In order to treat $\mathrm{OAB}$, pharmacotherapy with antimuscarinic agents has been used as a first line treatment for OAB. However, such medication has a strong placebo effect with marginal efficacy, and due to side effects such as dry mouth, compliance and
Table 1. Patient demographics

\begin{tabular}{|c|c|}
\hline Parameter & Analyzed group $(\mathrm{n}=85)$ \\
\hline Age (yr) & $56.7 \pm 15.9$ \\
\hline \multicolumn{2}{|l|}{ Gender } \\
\hline Male & $38(44.7)$ \\
\hline Female & $47(55.3)$ \\
\hline Follow-up period (mo) & $13.5 \pm 12.8$ \\
\hline \multicolumn{2}{|l|}{ Other surgery } \\
\hline Benign uterine surgery & $7(8.2)$ \\
\hline Benign anorectal surgery & $2(2.4)$ \\
\hline Benign spine surgery & $1(1.2)$ \\
\hline Others & $16(18.8)$ \\
\hline None & $58(68.2)$ \\
\hline \multicolumn{2}{|l|}{ Other diseases } \\
\hline Brain or spine disease & $3(1.2)$ \\
\hline Diabetes mellitus & $8(9.4)$ \\
\hline None & $75(88.3)$ \\
\hline \multicolumn{2}{|l|}{ Marital status } \\
\hline Married and living with partner & $63(74.1)$ \\
\hline Partner deceased & $3(3.5)$ \\
\hline Divorced & $4(4.7)$ \\
\hline Living separately & $1(1.2)$ \\
\hline Unmarried & $12(14.1)$ \\
\hline \multicolumn{2}{|l|}{ Occupation } \\
\hline Agriculture & $3(3.5)$ \\
\hline Manufacture & $4(4.7)$ \\
\hline Office worker & $6(7.1)$ \\
\hline Housewife & $8(9.4)$ \\
\hline Unemployed & $36(42.4)$ \\
\hline Retired & $10(11.8)$ \\
\hline Student & $5(5.9)$ \\
\hline \multicolumn{2}{|l|}{ Final education } \\
\hline Uneducated & $1(1.2)$ \\
\hline Elementary school & $6(7.1)$ \\
\hline Middle school & $11(12.9)$ \\
\hline High school & $23(27.9)$ \\
\hline College & $44(51.8)$ \\
\hline \multicolumn{2}{|l|}{ Average monthly income (KRW) } \\
\hline Less than $1,000,000$ & $16(18.8)$ \\
\hline $1,000,000-1,990,000$ & $14(16.5)$ \\
\hline $2,000,000-2,990,000$ & $16(18.8)$ \\
\hline $3,000,000-3,990,000$ & $16(18.8)$ \\
\hline $4,000,000-4,990,000$ & $7(8.2)$ \\
\hline More than $5,000,000$ & $14(16.5)$ \\
\hline
\end{tabular}

Values are presented as mean \pm standard deviation or number (\%). KRW, Korean Won (the currency of South Korea). 
Table 2. Change of questionnaire scores before and after bladder training

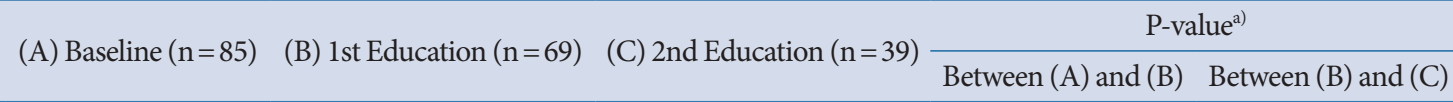

\begin{tabular}{|c|c|c|c|c|c|}
\hline \multicolumn{6}{|l|}{ ICIQ-OAB } \\
\hline Total & $6.2 \pm 2.2$ & $4.2 \pm 2.6$ & $3.4 \pm 1.6$ & $<0.001^{\star}$ & 0.058 \\
\hline Frequency & $1.7 \pm 1.2$ & $0.8 \pm 1.2$ & $0.5 \pm 0.6$ & $<0.001^{\star}$ & 0.054 \\
\hline Nocturia & $1.9 \pm 1.1$ & $1.3 \pm 1.0$ & $0.5 \pm 0.6$ & $<0.001^{\star}$ & 0.800 \\
\hline Urgency & $2.0 \pm 1.1$ & $1.5 \pm 1.2$ & $1.2 \pm 1.0$ & $0.004^{*}$ & 0.243 \\
\hline Incontinence & $0.6 \pm 0.8$ & $0.5 \pm 0.6$ & $0.5 \pm 0.6$ & 0.278 & 0.058 \\
\hline \multicolumn{6}{|l|}{ IPSS } \\
\hline IPSS-SS & $8.2 \pm 3.0$ & $5.6 \pm 2.7$ & $5.5 \pm 3.0$ & $<0.001^{\star}$ & 0.328 \\
\hline IPSS-VS & $9.0 \pm 6.0$ & $7.2 \pm 5.1$ & $6.3 \pm 4.5$ & $<0.001^{\star}$ & 0.809 \\
\hline IPSS-TS & $17.2 \pm 8.0$ & $12.8 \pm 6.8$ & $11.8 \pm 6.6$ & $<0.001^{\star}$ & 0.155 \\
\hline IPSS-Q8 & $86.8 \pm 32.1$ & $69.5 \pm 28.9$ & $67.1 \pm 28.1$ & $<0.001^{\star}$ & 0.385 \\
\hline \multicolumn{6}{|l|}{ OAB-q } \\
\hline Symptom severity & $23.4 \pm 7.5$ & $18.3 \pm 7.6$ & $17.3 \pm 6.5$ & $<0.001^{\star}$ & 0.273 \\
\hline Coping & $21.5 \pm 11.0$ & $17.6 \pm 9.4$ & $16.6 \pm 9.7$ & $<0.001^{\star}$ & 0.541 \\
\hline Concern & $18.2 \pm 8.3$ & $14.4 \pm 8.30$ & $14.0 \pm 6.6$ & $<0.001^{\star}$ & 0.833 \\
\hline Sleep & $14.1 \pm 6.7$ & $11.0 \pm 5.0$ & $10.8 \pm 4.7$ & $<0.001^{\star}$ & 0.680 \\
\hline Social interaction & $9.4 \pm 5.0$ & $8.0 \pm 3.9$ & $8.0 \pm 4.1$ & $0.001^{\star}$ & 0.599 \\
\hline HRQoL total & $63.0 \pm 26.3$ & $51.1 \pm 22.6$ & $49.6 \pm 22.6$ & $<0.001^{\star}$ & 0.564 \\
\hline \multicolumn{6}{|l|}{ SF-36 } \\
\hline Physical function & $24.5 \pm 5.0$ & $24.7 \pm 3.8$ & $25.3 \pm 3.9$ & 0.085 & 0.166 \\
\hline Role-physical & $15.2 \pm 4.6$ & $16.1 \pm 4.5$ & $16.0 \pm 4.0$ & $0.017^{*}$ & 0.235 \\
\hline Bodily pain & $4.4 \pm 2.3$ & $4.7 \pm 2.5$ & $4.7 \pm 2.3$ & 0.388 & 0.632 \\
\hline General health & $15.9 \pm 2.2$ & $16.2 \pm 1.9$ & $15.7 \pm 2.3$ & 0.193 & $0.047^{\star}$ \\
\hline Vitality & $14.4 \pm 2.9$ & $14.2 \pm 2.4$ & $14.1 \pm 2.3$ & 0.212 & 0.715 \\
\hline Social functioning & $6.0 \pm 0.8$ & $5.8 \pm 0.7$ & $6.1 \pm 0.98$ & 0.141 & 0.173 \\
\hline Role-emotional & $11.8 \pm 3.3$ & $12.3 \pm 3.2$ & $12.2 \pm 3.0$ & 0.110 & 0.711 \\
\hline Mental health & $16.9 \pm 2.7$ & $17.2 \pm 2.4$ & $17.0 \pm 2.5$ & 0.342 & 0.772 \\
\hline
\end{tabular}

Values are presented as mean \pm standard deviation.

ICIQ-OAB, International Consultation on Incontinence Questionnaire for overactive bladder; IPSS, International Prostate Symptom Score; SS, storage symptoms; VS, voiding symptoms; TS, total score; OAB-q, overactive bladder questionnaires; HRQoL, health-related quality of life; SF-36, short form 36-item health survey.

a) Analyzed by paired $t$-test. ${ }^{\star} \mathrm{P}<0.05$.

persistence rates are low. Behavioral treatments do not have such shortcomings, and have been used for several decades [4]. They have been adopted by several disciplines and are implemented in many different ways. The spectrum of behavioral treatments includes those that target voiding habits and life style, as well as those that train pelvic floor muscles to improve strength and control. What they all have in common is that they improve symptoms by teaching skills and by changing the patient's behavior. Among such treatments, BT is a behavioral intervention developed originally for the treatment of urge incontinence. The goal of BT is to break the cycle in which habitual frequent urination can reduce bladder capacity and lead to bladder overactivity, which in turn causes urge incontinence. BT introduces consistent incremental voiding schedules to reduce voiding frequency, increase bladder capacity, and restore normal bladder function [17]. BT offers an approach to OAB that avoids the side effects of anticholinergic medications, which is promising in that it aims to improve bladder control through systematic 
Table 3. Work productivity and activity impairment questionnaire

\begin{tabular}{|c|c|c|c|c|c|}
\hline & \multirow{2}{*}{$\begin{array}{c}\text { (A) Baseline } \\
(\mathrm{n}=85)\end{array}$} & \multirow{2}{*}{$\begin{array}{l}\text { (B) 1st Education } \\
(\mathrm{n}=69)\end{array}$} & \multirow{2}{*}{$\begin{array}{c}\text { (C) } 2 \mathrm{nd} \\
\text { Education }(\mathrm{n}=39)\end{array}$} & \multicolumn{2}{|c|}{ P-value ${ }^{\text {a) }}$} \\
\hline & & & & Between (A) and (B) & Between (B) and (C) \\
\hline \multicolumn{6}{|l|}{ General } \\
\hline Employed & $17(20.0)$ & $17(24.6)$ & $8(20.5)$ & $0.046 .6^{\mathrm{a}, *}$ & $1.000^{\mathrm{a})}$ \\
\hline Work hours $^{\mathrm{c})}$ & $44.6 \pm 19.1$ & $45.4 \pm 26.0$ & $61.7 \pm 18.2$ & $0.253^{\mathrm{b})}$ & $0.815^{\mathrm{b})}$ \\
\hline \multicolumn{6}{|c|}{ Work productivity and activity impairment dimensions } \\
\hline Work hours missed due to health & $0.6 \pm 1.7$ & $10.8 \pm 27.7$ & $3.1 \pm 4.1$ & $0.2774^{\mathrm{b})}$ & $0.0764^{\mathrm{b})}$ \\
\hline Work impairment due to health & $17.6 \pm 14.4$ & $24.1 \pm 29.2$ & $21.3 \pm 23.6$ & $0.820^{\mathrm{b})}$ & $0.465^{\mathrm{b})}$ \\
\hline Overall work impairment due to health & $17.3 \pm 14.6$ & $26.2 \pm 33.3$ & $23.0 \pm 25.0$ & $0.986^{\mathrm{b})}$ & $0.257^{\mathrm{b})}$ \\
\hline Activity impairment due to health & $34.2 \pm 28.3$ & $32.7 \pm 26.6$ & $31.3 \pm 27.6$ & $0.477^{\mathrm{b})}$ & $0.944^{\mathrm{b})}$ \\
\hline
\end{tabular}

Values are presented as number (\%) or mean \pm standard deviation.

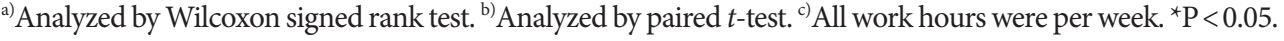

Table 4. Patients' perception of treatment benefit (PPTB) after bladder training and patients' perspective of bladder training

\begin{tabular}{|c|c|c|c|c|c|}
\hline & $\begin{array}{l}\text { After 1st } \\
\text { education } \\
(n=69)\end{array}$ & $\begin{array}{c}\text { After } 2 n d \\
\text { education } \\
(n=39)\end{array}$ & & $\begin{array}{l}\text { After 1st } \\
\text { education } \\
(n=69)\end{array}$ & $\begin{array}{c}\text { After } 2 \mathrm{nd} \\
\text { education } \\
(\mathrm{n}=39)\end{array}$ \\
\hline \multicolumn{3}{|l|}{ PPTB } & \multicolumn{3}{|l|}{ Patients' perspective of bladder training } \\
\hline \multicolumn{3}{|c|}{ How effective was this treatment for you? } & \multicolumn{3}{|c|}{ Which mode was most useful for holding urine? } \\
\hline Not effective & $6(8.7)$ & $2(5.1)$ & Nothing in particular & $12(17.4)$ & $6(15.4)$ \\
\hline Slightly effective & $36(52.2)$ & $19(48.7)$ & Avoiding going to bathroom & $19(27.5)$ & $10(25.6)$ \\
\hline Very effective & $27(39.1)$ & $18(46.2)$ & Deep breathing or thinking of some- & $16(23.2)$ & $8(20.5)$ \\
\hline \multicolumn{3}{|c|}{ How much did your symptoms improve after education? } & thing else & & \\
\hline $75-100 \%$ & $11(15.9)$ & $8(20.5)$ & Strong contraction of pelvic muscles & $20(29.0)$ & $15(38.5)$ \\
\hline $50-75 \%$ & $16(23.2)$ & $12(30.8)$ & No answer & $2(2.9)$ & $0(0)$ \\
\hline $25-50 \%$ & $21(30.4)$ & $10(25.6)$ & \multicolumn{3}{|c|}{ Which was most difficult when holding urine? } \\
\hline Less than $25 \%$ & $13(18.8)$ & $8(20.5)$ & $\begin{array}{l}\text { Abdominal pain or other physical } \\
\text { discomfort }\end{array}$ & $8(11.6)$ & $9(23.1)$ \\
\hline No improvement & $7(10.1)$ & $1(2.6)$ & I could not concentrate on anything & $16(232)$ & $7(179)$ \\
\hline Worsened & $0(0)$ & $0(0)$ & other activities & & \\
\hline \multirow[t]{3}{*}{ No answer } & $1(1.4)$ & $0(0)$ & Incontinence when holding urine & $19(27.5)$ & $10(25.6)$ \\
\hline & & & $\begin{array}{l}\text { After holding urine, experience of } \\
\text { difficulty voiding }\end{array}$ & $7(10.1)$ & $9(23.1)$ \\
\hline & & & No answer & $19(27.5)$ & $4(10.3)$ \\
\hline
\end{tabular}

Values are presented as number (\%).

changes in patient behavior and learning bladder control skills [18]. Therefore, we can also positively consider systematizing out BT protocol and broadening the range of application.

A few studies support the efficacy of BT, however, the shortterm follow-up of most studies is pointed out as a limitation, because $O A B$ usually requires long-term treatment [19]. In addition, although previous studies report that BT shows equivalent or superior efficacy compared to pharmacotherapy, many clinics do not have sufficient time, funding or appropriately qualified staff to provide a BT service, making it difficult to apply in clinical practice.

In our study, we analyzed the effect of a systematized BT in patients with iOAB. We measured the subjective symptom change of patients before and after BT with objective tools such as questionnaires. The questionnaire information of a few patients who did not visit our outpatient clinic after receiving both 
Table 5. Voiding diary

\begin{tabular}{lccccc}
\hline & (A) Baseline & (B) 1st & (C) 2nd & & \multicolumn{2}{c}{ P-value $^{\text {a) }}$} \\
\cline { 5 - 6 } & $(\mathrm{n}=38)$ & $\begin{array}{c}\text { Education } \\
(\mathrm{n}=38)\end{array}$ & $\begin{array}{c}\text { Education } \\
(\mathrm{n}=35)\end{array}$ & Between (A) and (B) & Between (B) and (C) \\
\cline { 5 - 6 } Day time frequency & $6.6 \pm 2.5$ & $6.8 \pm 3.1$ & $7.3 \pm 3.8$ & 0.502 & 0.730 \\
Nocturia & $1.2 \pm 1.1$ & $1.2 \pm 1.4$ & $0.7 \pm 0.9$ & 1.000 & 0.056 \\
Total voiding count & $7.8 \pm 2.6$ & $8.1 \pm 3.5$ & $7.9 \pm 3.8$ & 0.547 & 0.743 \\
Mean voided volume & $239.2 \pm 84.4$ & $234.6 \pm 83.0$ & $215.4 \pm 86.0$ & 0.604 & 0.394 \\
Maximal voided volume & $355.3 \pm 111.5$ & $386.3 \pm 127.3$ & $326.3 \pm 130.9$ & $0.047^{*}$ & 0.076 \\
Nocturia index & $1.0 \pm 0.8$ & $0.8 \pm 0.7$ & $0.5 \pm 0.7$ & 0.078 & $0.045^{*}$ \\
Nocturnal polyuria index & $0.19 \pm 0.15$ & $0.17 \pm 0.15$ & $0.11 \pm 0.13$ & 0.167 & $0.024^{*}$ \\
\hline
\end{tabular}

Values are presented as mean \pm standard deviation.

a) Analyzed by paired $t$-test. ${ }^{*} \mathrm{P}<0.05$.

sessions of BT was obtained by a follow-up telephone interview. We considered this as reliable, because the patients' recollection of their most recent status was accurate. The significant improvement of ICIQ-OAB scores after the first BT session shows that BT can be effective in improving the subjective symptoms of the patients.

The results of the ICIQ-OAB questionnaire are interesting, in that frequency, nocturia, and urgency all improved, yet the improvement of incontinence was not significant. In previous studies, incontinence was proved to be significantly improved by BT in women. Our study did not show such significant improvement, probably because incontinence is a strong symptom, not easy to defer by BT alone. Our patients mostly suffered from OAB-dry [20]. Our study showed significant improvement in symptoms that were previously considered to be predominant in male patients [18]. Although our study included more female patients than male patients, such results suggest the broader range of applicability of $\mathrm{BT}$ in the future.

The SF-36 showed significant improvement in only physical symptoms and vitality, but this can be attributed to the fact that this questionnaire is a generic questionnaire, with lower specificity compared to the other questionnaires [21]. The reduction of loss of working hours, and increase of actual working hours after BT measured by the WPAI-GH show that BT can be beneficial in increasing productivity, and thus increase patient satisfaction of work efficacy. The replies of the patients to the PРTB after systematized BT also provide valuable information. Our results suggested that a $\mathrm{BT}$ can be effective in improving symptoms and QoL of patients with $\mathrm{OAB}$, and patients highly considered the program to be useful after completion of both sessions. The fact that patients actually considered strong contrac- tion of pelvic muscles to be useful in holding urine indirectly suggests the usefulness of BT (Table 4).

Why the statistical significance of the effect of BT was lower after the second session than the first session is worth consideration. We attributed this difference to the fact that patients already knew the contents of $\mathrm{BT}$ after the first session, and therefore, the effect of the second BT might have been weaker. In addition, most of the patients who perceived the BT to be effective after the first session did not visit our institution for a second follow-up. The low number of patients at final follow-up could also be an indicator of the effectiveness of BT.

According to the voiding diaries, although the number of daytime voids showed no change after BT, the maximal voided volume increased significantly after first BT. In the other questionnaires we analyzed, the urgency the patients felt per each void significantly improved. The reason the number of voids did not improve on voiding diary analysis was probably due to a selection bias due to the small number of patients who filled up voiding diaries on follow-up. Therefore, detailed analysis of number of daytime voids is necessary in the future

This study has a few limitations. First of all, we lost quite a few patients at final follow-up, thus this limited number of patients may have created selection bias in our investigation. Also, quite a few patients failed to record their voiding diaries, causing a loss in information of number of voids, and nocturia variables. In addition, this study is a single arm study. In the future, a prospective randomized controlled study is warranted to explore the efficacy of BT or pharmacotherapy in iOAB. Also, we excluded neurologic OAB patients, which would also benefit from additional analysis in the future.

Our study demonstrated that BT in patients diagnosed with 
iOAB is effective in improving QoL, work productivity, and voiding symptoms, and is perceived to be useful in improving symptoms. In order to obtain more information, more detailed studies are necessary in the future.

\section{CONFLICT OF INTEREST}

No potential conflict of interest relevant to this article was reported.

\section{ACKNOWLEDGEMENTS}

We are obliged to Mrs. Yu Kyung Lee for valuable help in database management.

\section{REFERENCES}

1. Abrams P, Artibani W, Cardozo L, Dmochowski R, van Kerrebroeck P, Sand P, et al. Reviewing the ICS 2002 terminology report: the ongoing debate. Neurourol Urodyn 2009;28:287.

2. Hubeaux K, Deffieux X, Raibaut P, Le Breton F, Jousse M, Amarenco G. Evidence for autonomic nervous system dysfunction in females with idiopathic overactive bladder syndrome. Neurourol Urodyn 2011;30:1467-72.

3. Griebling TL. Best treatment for overactive bladder if behavioral treatment and anticholinergics fail. Sacral nerve stimulation. J Urol 2011;185:2024-6.

4. Arnold J, McLeod N, Thani-Gasalam R, Rashid P. Overactive bladder syndrome: management and treatment options. Aust Fam Physician 2012;41:878-83.

5. Van Kerrebroeck PE. Does conservative management really benefit patients with OAB? Curr Urol Rep 2012;13:348-55.

6. Wyman JF, Burgio KL, Newman DK. Practical aspects of lifestyle modifications and behavioural interventions in the treatment of overactive bladder and urgency urinary incontinence. Int J Clin Pract 2009;63:1177-91.

7. Cho SY, Lee SL, Kim IS, Koo DH, Kim HJ, Oh SJ. Short-term effects of systematized behavioral modification program for nocturia: a prospective study. Neurourol Urodyn 2012;31:64-8.

8. Acquadro C, Kopp Z, Coyne KS, Corcos J, Tubaro A, Choo MS, et al. Translating overactive bladder questionnaires in 14 languages. Urology 2006;67:536-40.

9. Oh SJ, Son H, Kim SW, Lee KS, Choo MS, Kim SO, et al. Psychometric properties of the Korean version of the overactive bladder questionnaire (OAB-q) in a Korean population. Int Neurourol J
2012;16:77-85.

10. Han SS, Kim KW, Na KY, Chae DW, Kim YS, Kim S, et al. Quality of life and mortality from a nephrologist's view: a prospective observational study. BMC Nephrol 2009;10:39.

11. Kosinski M, Keller SD, Hatoum HT, Kong SX, Ware JE Jr. The SF36 Health Survey as a generic outcome measure in clinical trials of patients with osteoarthritis and rheumatoid arthritis: tests of data quality, scaling assumptions and score reliability. Med Care 1999; 37(5 Suppl):MS10-22.

12. Kim HS, Harada K, Miyashita M, Lee EA, Park JK, Nakamura Y. Use of senior center and the health-related quality of life in Korean older adults. J Prev Med Public Health 2011;44:149-56.

13. Coyne KS, Sexton CC, Thompson CL, Clemens JQ, Chen CI, Bavendam $\mathrm{T}$, et al. Impact of overactive bladder on work productivity. Urology 2012;80:97-103.

14. Pleil AM, Coyne KS, Reese PR, Jumadilova Z, Rovner ES, Kelleher CJ. The validation of patient-rated global assessments of treatment benefit, satisfaction, and willingness to continue--the BSW. Value Health 2005;8 Suppl 1:S25-34.

15. Waine E, Hashim H, Abrams P. Management of the overactive bladder: a review of pharmacological therapies and methods used by the urological specialist. Can J Urol 2007;14:3478-88.

16. Sung W, You H, Yoon TY, Lee SJ. Socioeconomic costs of overactive bladder and stress urinary incontinence in Korea. Int Neurourol J 2012;16:23-9.

17. Burgio KL. Behavioral treatment of urinary incontinence, voiding dysfunction, and overactive bladder. Obstet Gynecol Clin North Am 2009;36:475-91.

18. Burgio KL, Goode PS, Johnson TM, Hammontree L, Ouslander JG, Markland AD, et al. Behavioral versus drug treatment for overactive bladder in men: the Male Overactive Bladder Treatment in Veterans (MOTIVE) Trial. J Am Geriatr Soc 2011;59:2209-16.

19. Gormley EA, Lightner DJ, Burgio KL, Chai TC, Clemens JQ, Culkin DJ, et al. Diagnosis and treatment of overactive bladder (non-neurogenic) in adults: AUA/SUFU guideline. J Urol 2012;188(6 Suppl): 2455-63.

20. Anger JT, Le TX, Nissim HA, Rogo-Gupta L, Rashid R, Behniwal A, et al. How dry is "OAB-dry"? Perspectives from patients and physician experts. J Urol 2012;188:1811-5.

21. Ware JE Jr, Kosinski M, Bayliss MS, McHorney CA, Rogers WH, Raczek A. Comparison of methods for the scoring and statistical analysis of SF-36 health profile and summary measures: summary of results from the Medical Outcomes Study. Med Care 1995;33(4 Suppl):AS264-79. 